\title{
O DELOVANJU IN GOVORU POLITIČNIH ELIT SKOZI OPTIKO PARLAMETRA
}

\section{Tina LENGAR VEROVNIK}

Univerza v Ljubljani, Fakulteta za družbene vede

ZRC SAZU, Inštitut za slovenski jezik Frana Ramovša

\section{Eva VRTAČIČ}

Univerza v Ljubljani, Fakulteta za družbene vede

\section{Tanja OBLAK ČRNIČ}

Univerza v Ljubljani, Fakulteta za družbene vede

Lengar Verovnik, T., Vrtačič, E., Oblak Črnič, T. (2016): O delovanju in govoru političnih elit skozi optiko Parlametra. Slovenščina 2.o, 4 (2): 38-66.

URL: http://www.trojina.org/slovenscina2.o/arhiv/xxxxx/x/Slo2.o_xxxx_x_xx.pdf.

Članek problematizira več vidikov delovanja in govora etablirane politične elite $\mathrm{v}$ kontekstu novega spletnega orodja Parlameter. Pojav spleta in digitalnih prostorov izražanja pri tem razumemo kot platformo, ki jezik kot družbeni fenomen tudi kritično analizira. Parlameter namreč dopušča, da že prisotno govorico, ki ima pomemben kontekst, saj gre za poslance oz. zakonodajne odločevalce, ki soustvarjajo javno kulturo, podrobneje analiziramo s pomočjo raznolikih algoritmov in strukturnih mehanizmov - od rabe jezika do prisotnosti in odločanja $\mathrm{v}$ državnem zboru. $\mathrm{V}$ prispevku predstavljamo zlasti avtomatizirane in druge analize, ki jih spletišče ponuja na ravni govora posameznikov in poslanskih skupin v trenutnem parlamentarnem sklicu. Ker pa Parlameter kot novo analitično orodje poleg jezikovno-stilnih dimenzij ponuja tudi nadzorovalno funkcijo delovanja poslancev in poslank ter njihovih odločitev, $\mathrm{v}$ prvem delu prispevka predstavljamo preostale ravni morebitnih analiz in jih umeščamo $\mathrm{v}$ širši kontekst digitalizacije institucionalne politike.

Ključne besede: državni zbor, analiza govorov, digitalne platforme, Parlameter 


\section{UVOD}

Parlamentarna demokracija kot politični sistem sledi vnaprej določenim postopkom in statutarnim pravilom, kjer volitve v državni zbor predstavljajo le eno od temeljnih državljanskih pravic in dolžnosti, prek katerih lahko polnoletni državljani izrazijo svoje osebne politične preference. Rezultat (bodisi rednih bodisi izrednih) volitev je viden $\mathrm{v}$ izboru kandidatov in posameznih političnih strank, ki zasedejo parlamentarno sestavo za obdobje štirih let.

Politični sistem Republike Slovenije na zakonodajni ravni sestavlja 90-članski parlament, ki sprejema in potrjuje zakone ter izvršuje vrsto drugih političnih procedur. Državljani se lahko z delom parlamenta seznanijo na več možnih načinov, odvisno od stopnje njihove osebne vključenosti v politično delovanje in širše družbeno-politično dogajanje. Medijska podprtost in informiranost o dogajanju v parlamentu je omogočena prek televizijskih prenosov na slovenski javni televiziji na posebnem programu, TV Slovenija 3. Tretji program javne televizije posnetke sej delovnih teles in državnega zbora objavlja tudi na svojem spletnem mestu. Poleg medijskega poročanja o delu v parlamentu je eden od možnih kanalov informiranja tudi spletno mesto parlamenta, ki ponuja vpogled v zapisnike parlamentarnih sej, sprejete zakone oz. zakonska določila, predloge sklepov parlamentarnih odborov itd.

Kljub medijski pozornosti do parlamentarnih zadev se zdi, da državljanom primanjkuje neposredne seznanitve ali neposrednega uvida $\mathrm{v}$ delo poslancev in poslank ter poslanskih skupin, saj omenjeni medijski kanali skupaj z novimi družbenimi omrežji, prek katerih se politiki lahko predstavljajo, ohranjajo moč nad selekcijo tem in vsebinami poročanja $\mathrm{v}$ rokah samih elit. Možnosti za neposredno sodelovanje oz. odzivanje državljanov na izbire in odločitve poslancev so tako medijskim kanalom navkljub še vedno omejene.

Enega prvih poskusov, ki naj bi državljanom povečal vpogled v delo parlamenta in $\mathrm{s}$ tem ponudil nadzor nad izrečenim $\mathrm{v}$ procesu parlamentarnih razprav, predstavlja digitalna platforma Parlameter, ki jo razvija Danes je nov dan, 
Inštitut za druga vprašanja. ${ }^{1}$ Parlameter je spletno orodje, ki z raznolikimi analizami glasovanj in transkriptov govorov poslancev lajša spremljanje dela $\mathrm{v}$ državnem zboru. Skozi vizualizacijo podatkov in tehnološko napredno modularno zasnovo veča transparentnost delovanja najpomembnejše demokratične institucije, saj tako splošnim uporabnikom kot razvijalski skupnosti in novinarski stroki omogoča učinkovit vpogled $\mathrm{v}$ odločevalski proces. Po dveh letih razvoja je bil Parlameter v okviru razpisa Digital Innovation Fund s strani Googlove fundacije Digital News Initiative prepoznan kot izjemno obetajoča tehnološka rešitev in njihovo financiranje predstavlja prvi tovrstni vložek v Slovenijo.

Namen članka je analizirati stanje na področju spletne dostopnosti podatkov in informacij o delu poslancev, pregledati obstoječe slovenske rešitve (tako državne kot civilnodružbene), našteti tuje dobre prakse, nato pa preliminarno podrobneje predstaviti Parlameter, ki bo sicer začel delovati do konca leta 2016. Orodje je še v razvoju, zato je namen analize tudi preverjanje in ponovni premislek o njegovih metodoloških in konceptualnih odločitvah. Tudi s tega vidika - zlasti pa z vidika možnosti, ki jih odpira jezikoslovcem in drugim uporabnikom - so v drugem delu prispevka predstavljene jezikovno-stilne analize, ki jih bo nudil Parlameter kot dinamičen jezikovni vir.

\section{PARLAMENTI IN POSLANCI NA SPLETU}

Navzočnost državnih in drugih političnih institucij na spletu v današnjem času ni nikakršna novost, ostaja pa pomemben družbeni dejavnik, ki kaže tako na tehnološko »razvitost « etablirane politike kot tudi na načine, kako institucije skoznje dojemajo državljane. Zato je način digitalnega upovedovanja ključnih

\footnotetext{
${ }^{1}$ Inštitut je v prvem mandatu od ustanovitve vodila ena od soavtoric prispevka Eva Vrtačič, ki tudi aktivno sodeluje zlasti pri konceptualnih vidikih orodja Parlameter. Tanja Oblak Črnič je bila v istem času članica znanstvenega sveta inštituta. Snovalci Parlametra so kot člani in članice v namen tukajšnjega prispevka vsem avtoricam omogočali dostop do informacij o samem orodju in vseh naknadnih analizah, za kar se jim iskreno zahvaljujemo.
} 
predstavnikov vej oblasti - izvršne, zakonodajne in sodne - še kako pomemben indikator komunikacijske odprtosti, javne transparentnosti in participativnih zmožnosti v t. i. digitalni dobi.

Slovenske vladne institucije, državni zbor in druge ustanove državne uprave so se v spletna okolja prvič pričela izraziteje pre(d)stavljati na prelomu v leto 2000, pri čemer so dosedanje analize njihovih spletnih predstavitev (glej Oblak 2003; Oblak 2010; Oblak in Prodnik 2014) pokazale na v informativnem smislu dobro pozicioniranost političnih akterjev, ki pa od zgodnjih začetkov dalje $\mathrm{v}$ odnosu do razpiranja komunikacijskih in participativnih praks državljanov ostajajo še vedno precej zaprte. Večina etablirane politike spletna prizorišča bolj razume kot lasten medij za informiranje in posredovanje novic ter kot prostor za utrjevanje lastnih pozicij, manj pa kot učinkovit kanal za javno komuniciranje z javnostmi in državljani.

\subsection{Začetki vstopa parlamentov na splet}

Posamezne analize spletnih predstavitev nacionalnih parlamentov $\mathrm{z}$ zanimivimi primeri z implementacijo interneta na Škotskem, v Angliji, Avstraliji in na Danskem segajo že v pozna 90. leta 20. stoletja (glej npr. Coleman, Taylor in van de Donk 1999; Lofgren in dr. 1999; Taylor in Burt 1999). Zgodnje študije so pri evalvaciji spletnih predstavitev parlamentov pregledovale več dejavnikov: a) stopnjo spodbujanja javne participacije pri oblikovanju politik in možnosti povratnega odziva; b) dostop do urnikov posameznih parlamentarnih razprav in možnosti vključevana državljanov vanje; c) obstoj spletnih forumov o izbranih temah parlamentarnih razprav; d) preprost dostop do javnih politik in zakonodajnih dokumentov ter e) dostop do mehanizmov glasovanj (Taylor in Burt 1999: 147-148). Ena od skupnih ugotovitev takratnih analiz je govorila $\mathrm{v}$ prid tezi, da se prvi projekti implementacije ustavijo pri izrabi funkcionalnosti spletnih mest, pri čemer se usmerjajo prvenstveno $\mathrm{k}$ »tradicionalnim « uporabnikom, torej $\mathrm{k}$ politikom in novinarjem, manj pa izkoriščajo interaktivne in multimedialne potenciale 
spleta. Bellamy in Rabb (1999) sta skušala različne izkušnje teh zgodnjih študij povzeti s pomočjo t. i. »informatizacijske lestve« (1999: 158), ki odraža različno stopnjo vključevanja internetnih uporabnikov v spletne predstavitve političnih akterjev oz. institucij: na najnižjo letev spadajo poskusi, ki z uporabo spletnih tehnologij težijo predvsem k izboljšanju delovanja samih institucij; na drugo se uvrščajo primeri, kjer tehnologije nastopajo kot orodja za dostop do različnih virov informacij; na tretjo se povzpnejo primeri, ki kot element sodelovanja med institucijo in uporabniki že vpeljujejo interaktivne komunikacijske poti; čisto na vrhnjo letev pa sodijo poskusi, ki implementirajo možnost kolektivnega sodelovanja. $Z$ višino uvrstitve na informatizacijski lestvi se torej povečuje vključenost v sodelovanje in $\mathrm{s}$ tem veča stopnja demokratizacije kolektivnega delovanja prek spletnih platform.

Kljub različnim poskusom evalvacije spletnih mest pa so študije, ki bi ponujale poglobljene vpoglede $\mathrm{v}$ analizo podobnosti in razlik med izbranimi političnimi institucijami, redke. Ena prvih kvantitativnih primerjalnih raziskav spletnih mest državnih parlamentov in parlamentarnih političnih strank $\mathrm{v}$ EU z naslovom "Evaluation of the use of new technologies in order to facilitate democracy in Europe" (EUI 2003), v kateri je bila zajeta tudi Slovenija, je temeljila na vzorcu 144 spletnih predstavitev političnih strank in 38 zakonodajnih teles. Analiza spletnih predstavitev je bila razdeljena glede na različne namene in oblike uporabe spleta: vključevala je informativnost strani, prijaznost oz. preglednost strani za uporabnike, obstoj bilateralne oz. konverzacijske interaktivnosti (e-pošta), multilateralne oz. konzultacijske interaktivnosti (participacija, forumi), hipertekstualnost kot medsebojno povezanost samih spletnih strani in mobilizacijski potencial strani. Študija je pokazala, da so takratni nacionalni evropski parlamenti prek spletnih platform uresničevali predvsem dve funkciji: posredovanje informacij (68 \%) ter dostop do poslancev in drugih zaposlenih prek e-pošte (69 \%), najmanj razvita pa je bila raven multilateralne interaktivnosti (14 \%). Uporabniška dostopnost je 
sicer dosegla višjo oceno, a je bila še vedno podpovprečna (43\%). ${ }^{2}$

V eni zadnjih primerjalnih empiričnih študij parlamentarnih spletnih mest (glej Joshi in Rosenfield 2013) so se avtorji omejili posebej na interaktivno plat dostopa do poslancev in poslank prek spleta. Na primeru 184 držav v celotnem vzorcu spletnih mest so med drugim ugotovili, da se je interaktivnost oz. dostopnost glede na podatke iz leta 2000 izboljšala le v manjši meri (2013: 534): 82 \% vseh strani je imelo naveden seznam vseh poslancev, le dve tretjini (69 \%) jih je navedlo podatek o članstvu v političnih strankah in enak delež strani je vseboval fotografijo poslanca. Dostop do e-pošte poslanca je ponujala manj kot polovica strani (44 \%), telefonsko številko tretjina (32 \%), službeni naslov četrtina (25\%). Kot podobno nizka se je pokazala prisotnost poslancev na družbenih omrežjih: na celotnem vzorcu je le petina spletnih mest $\mathrm{z}$ dostopom do družbenih omrežij, pri čemer je najvišji delež značilen za države ZDA (59 \%) oz. Evrope (27\%).

\subsection{Slovenske politične institucije in splet}

Primer angleškega spletnega portala www.parliament.uk velja še danes za zgled, kako naj se zakonodajne politične institucije etablirane politike javno predstavljajo prek novih digitalnih orodij. Današnje spletno mesto slovenskega državnega zbora (www.dz-rs.si) je še vedno prvenstveno samopredstavitveno. Državni zbor kot institucija nima profila na nobenem spletnem omrežju, prav tako ni prisoten na Twitterju. Seje so sicer redno javno predvajane na posebnem kanalu slovenske RTV, prav tako so na spletu dostopni vsi zapisi in gradiva sej parlamenta, odborov in drugih parlamentarnih teles. Vključevanje državljanov prek spleta v samo delo parlamenta, možnosti za oddajo predlogov ali peticij v obravnavo, kontaktiranje poslancev in podobne mobilizacijske

2 Spletna predstavitev takratnega slovenskega parlamenta je pri vseh ocenah dosegla podpovprečne rezultate, $v$ vrhu pri posameznih indeksih pa so izstopali parlamenti Nemčije, Velike Britanije, Francije, Evropske unije in Grčije. 
možnosti pa so še vedno povsem odsotne. Angleški parlament, nasprotno, na slikovit in atraktiven način ponuja vse našteto in še več.

Ne glede na digitalno statičnost slovenskega parlamenta pa to ne pomeni, da se politični akterji ne pojavljajo individualno na lastnih komunikacijskih spletnih kanalih in drugih platformah, kot sta Facebook in Twitter. Vendar so zaključki različnih študij zopet precej podobni nekdanjim analizam spletnih mest: politiki nove digitalne kanale uporabljajo predvsem kot orodja za (samo)promocijsko komuniciranje, manj pa za dejansko razpravljanje ali sodelovanje z drugimi (glej npr. Golbeck in dr. 2010; Dahlgren 2013; Mance 2014). Tudi nedavna analiza slovenskih spletnih mest političnih institucij (glej Oblak in Prodnik 2014) je pokazala, da je "personalna politika« v tem kontekstu primerjalno gledano celo manj aktivna kot institucionalna: poslanci se sicer v večji meri prikazujejo skozi svoje fotografije, a so pri vseh drugih elementih institucije informacijsko gledano bogatejše: več imajo vsebin o lastnem delovanju, večkrat so opremljene s koledarji aktivnosti, več imajo rubrik za medije in večkrat ponujajo informacije tudi $\mathrm{v}$ tujem jeziku. Samopromocijskost in posledično še bolj izrazita individualizacija političnih akterjev $\mathrm{v}$ prostore družbenih medijev in posredovanih komunikacijskih platform vnaša torej še manj možnosti za realizacijo participativnih in sodelovalnih komunikacijskih poti. Uporabniki oz. državljani so na ta način sicer vključeni v individualistično motivirane komunikacijske kanale, a jih prvenstveno lahko uporabljajo kot enosmerne medije, skozi katere politični akterji še dodatno utrjujejo lastne pozicije moči.

Temeljni vir za informacije o delu slovenskega parlamenta je njegova uradna spletna stran, ki pa prikazuje le gole podatke brez konteksta, razlage ali 
vizualizacij, prav tako ne obstaja noben API3, ki bi omogočal zunanji dostop do podatkov za tovrstne kontekstualizacije. Pomemben civilnodružbeni mejnik v transparentnosti predstavlja tako spletno mesto delajozate.si, kjer uporabnik lahko pregleduje glasovanja in transkripte poslanskih govorov. Drugi primer zakonodajni monitor - se fokusira bolj na proceduro sprejemanja zakonov in ostalih zakonodajnih procesov kot na same poslance. Tudi nekateri tiskani mediji so začeli uporabljati principe t. i. podatkovnega novinarstva (npr. Dnevnikov Objektiv), za katero je značilno pretvarjanje podatkov v informacije $\mathrm{s}$ pomočjo vizualizacij in postavljanja v kontekst. Tovrstnih dobrih praks ni veliko tudi zaradi slabe (strojne) dostopnosti podatkov, zato je eden od ciljev orodij, kot je Parlameter, predvsem olajšati delo tako novinarjem kot razvijalcem, saj bo ponujal dostop do že obdelanih podatkov.

\section{O PARLAMETRU - IDEJNA ZASNOVA, CILJI IN STRUKTURA ORODJA}

Danes je nov dan je nastal jeseni 2012 kot sopotnik, integralni del in podpornik vstajniških gibanj. Od septembra 2013 deluje kot inštitut, ki se osredotoča na (digitalno) politično participacijo, transparentnost in nadzor. Delovanje inštituta izhaja iz razumevanja demokracije kot nenehnega procesa, družbene pogodbe kot stalne in vključujoče razprave ter politične participacije kot odgovornosti za lastno opolnomočenje. S projekti v obliki digitalnih intervencij, ki uporabljajo inovativne prijeme spletnega komuniciranja, se odziva na aktualne družbenopolitične dogodke, ozavešča, opozarja in aktivira ljudi. Do sedaj je v okviru inštituta nastala vrsta civilnodružbenih digitalnih projektov, med drugim denimo spletna kampanja ob referendumu o redefiniciji zakonske zveze, spletna kampanja, ki je opozarjala na izključenost slepih in slabovidnih

3 API (angl. application programming interface) je nabor postopkov, protokolov in orodij za ustvarjanje programske opreme in aplikacij. API demokratizira dostop do podatkov in algoritmov, ko priskrbi sestavne dele, iz katerih nato programerji sestavljajo novo programsko opremo. 
iz digitalnih okolij, pa kritični odgovor na kampanjo Mestne občine Ljubljana Človek, čuvaj svoje mesto, ki je preizpraševala prevladujočo definicijo vandalizma. V sodelovanju z Open Society Foundation in Inštitutom za delavske študije je nastalo spletno mesto neenakost.je, ki razlaga ključne koncepte in kontekste ekonomske neenakosti. Poleg omenjenih velja izpostaviti še digitalni eksperiment $\mathrm{v}$ sodelovanju $\mathrm{s}$ študenti Biotehniške fakultete in Fakultete za arhitekturo, ki je predstavil dve različni možni viziji razvoja javnega prostora, ter številne ad hoc intervencije in intervencije ob aktualnih temah in dogodkih.4 Parlameter je eden od zadnjih rezultatov dela inštituta.

Parlameter zbira podatke, ki so slabo dostopni, skriti v množici informacij, strojno neberljivi ali težko razumljivi, in jih ureja $\mathrm{v}$ informacije, ki so pospremljene $\mathrm{z}$ vizualizacijami. Najširši cilj orodja je povečati politično participacijo prebivalcev preko povečanja transparentnosti in dostopnosti podatkov o delovanju parlamenta. Olajšano bo raziskovanje po podatkih za namene novinarskega dela, zaradi odprtokodne zasnove celotnega orodja pa bodo razvijalci lahko jemali zbrane podatke in analize ter jih prevajali v druga orodja ali aplikacije.

Podobne rešitve, kot je Parlameter, v tujini že obstajajo. Britanski theyworkforyou.com denimo ponuja vpogled $\mathrm{v}$ glasovanja in njihovo kontekstualizacijo tako znotraj posamezne politične stranke kot celega parlamenta. Poljski Sejmometr ponuja raznolike načine organizacije in pregleda rezultatov glasovanj, ameriška aplikacija Capitol Words omogoča iskanje po transkriptih govorov in izrisuje uporabo posameznih besed skozi čas, Open Congress pa računa, kdo od ameriških kongresnikov si je po glasovanju najbližje in kdo najdlje.

Analize, ki jih ponuja Parlameter, lahko v grobem razdelimo na tiste, ki se

4 Pregled dosedanjih projektov inštituta je dostopen na spletnem mestu http://danesjenovdan.si/projekti. 
ukvarjajo z nadzorovalno-odločevalskimi, in tiste, ki se ukvarjajo z jezikovnostilnimi vidiki. Prvi del analiz na podlagi javno dostopnih podatkov omogoča empirični »monitoring « prisotnosti, glasovanj in ostalih delovnih obveznosti poslancev ter je v tem smislu popolnoma objektiven, medtem ko drugi del analiz vsebuje tudi jezikovnostilistične analize, ki vsaj deloma že temeljijo na uredniških odločitvah. Izbor posameznih kvalifikatorjev iz SSKJ in SNB (gl. 3.2 in dalje) je že vsebinska odločitev, zato bo zlasti ta del analiz treba temeljito preverjati in ves čas posodabljati.

Ne glede na te omejitve pa cilj Parlametra ni ponujati interpretacij ali vsebinskih sodb, pač pa omogočiti čim bolj objektiven in empiričen kontekst delovanja poslancev in dogajanja $\mathrm{v}$ parlamentu, ki ga lahko uporabniki samostojno tolmačijo skladno $\mathrm{z}$ njihovim raziskovalnim, novinarskim, političnim idr. interesom in védenjem.

\subsection{Nadzorovalno-odločevalski vidiki}

Parlameter je namenjen najširši splošni javnosti, za specifične rabe pa novinarjem in raziskovalcem. Orodje je strukturirano na način, da ima vsak poslanec oz. poslanka svoj profil, ki poleg osnovne predstavitve zajema še rezultate analiz njihovih glasovanj in govorov. Podobne profile imajo tudi poslanske skupine, na njih pa se izpisujejo povprečne vrednosti rezultatov analiz njihovih članov (Slika 1). 


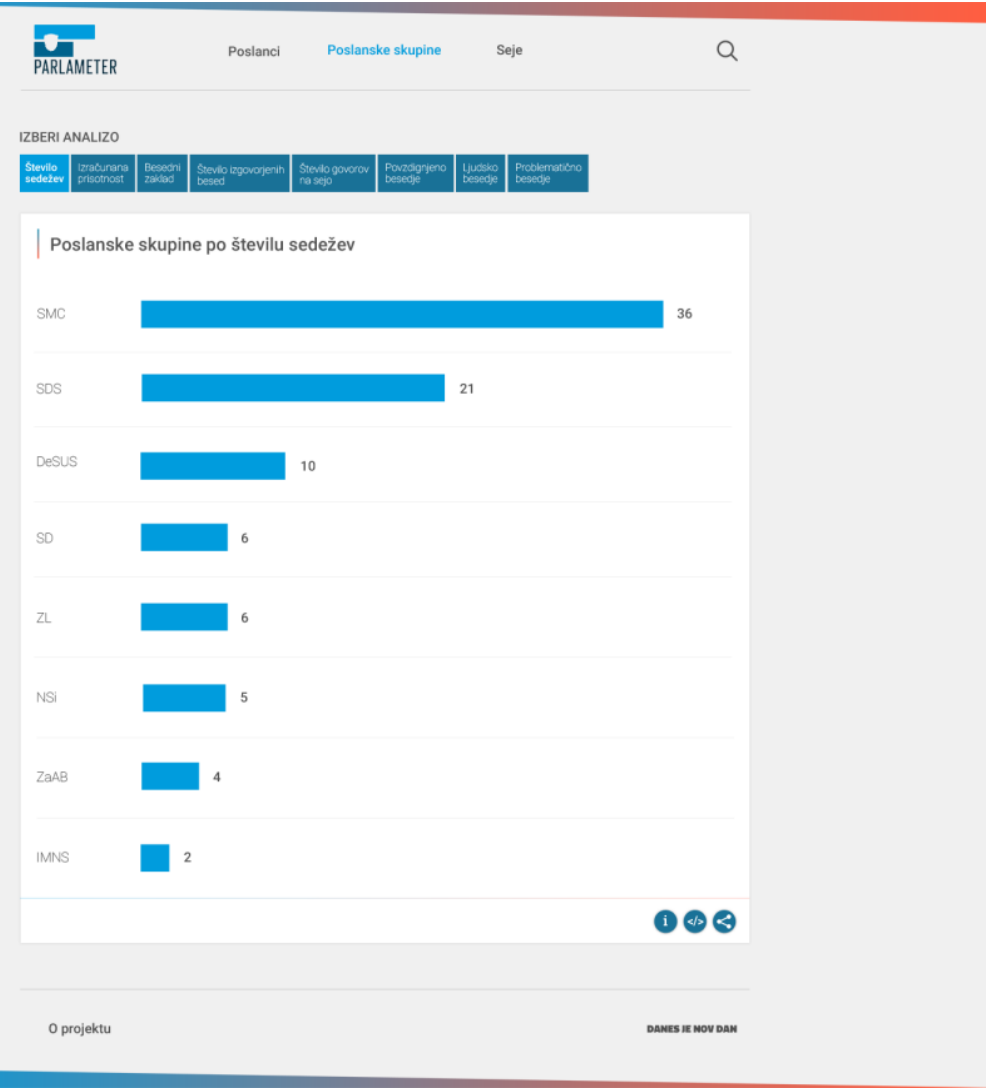

Slika 1: Zbirnik rezultatov analiz po posameznih poslanskih skupinah.

$\mathrm{Na}$ podlagi glasovanj so poslanci in poslanke $\mathrm{v}$ t. i. političnem kompasu postavljeni v dvodimenzionalni prostor, kjer se vidi, kateri posamezniki so si v odločitvah blizu, kdo si je najbolj oz. najmanj podoben, računa pa se tudi odstopanje glasovanj posameznikov glede na večinske odločitve poslanskih skupin, ki jim pripadajo, ter prisotnost na sejah. Uporabniški vmesnik omogoča filtriranje glasovanj po odborih oz. ministrstvih.

Podatki, ki jih Parlameter obdeluje in prikazuje, so pridobljeni z branjem HTML datotek, saj je bil to ob začetku zasnove orodja edini možni način spremljanja dela $\mathrm{v}$ državnem zboru. Ta metoda je pomanjkljiva $\mathrm{v}$ smislu zanesljivosti, hkrati pa terja tudi veliko programerskega dela. Pri dosedanjem 
razvoju orodja je $\mathrm{v}$ sodelovanju $\mathrm{z}$ državnim zborom prišlo do načelnega dogovora, da bo parlamentarni informacijskih sektor v nekaj letih vzpostavil API (gl. opombo 3), ki bo zajem podatkov avtomatiziral. Glede na to zavezo lahko rečemo, da ima Parlameter pozitivne učinke na dostopnost in transparentnost podatkov o odločevalskem procesu že pred dokončanjem in objavo orodja. Nasploh je poleg analiz, ki jih ponuja, Parlameter pomemben tudi kot oblika pritiska na institucijo državnega zbora, in sicer v smeri odprtosti in dostopnosti podatkov.

Parlameter deluje na način izpisovanja med seboj neodvisnih kartic, ki jih je mogoče enostavno vdelati v druga spletna mesta, hkrati pa ima vsaka kartica tudi unikaten spletni (URL) naslov in tako predstavlja samostojen kos internetne vsebine. To je posebej pomembno $\mathrm{z}$ vidika uporabnikov kot državljanov, ki lahko enostavno dostopajo do specifičnih vsebin s Parlametra, jih uporabljajo, izpostavljajo ali naslavljajo. Poleg orodja Parlameter bo inštitut Danes je nov dan v brezplačno uporabo ponudil tudi API Parlalize, ki razvijalcem ponuja JSON5 podatke, pripravljene za kartice (Slika 2) ${ }^{6}$.

5 JSON (angl. JavaScript Object Notation) je standardiziran format, ki uporablja ljudem berljiv tekst za prenos podatkovnih objektov, sestavljenih iz parov atributov in vrednosti. ${ }^{6}$ Slikovni material, uporabljen v članku, ne prikazuje dejanskih podatkov. Namenjen je zgolj ilustraciji delovanja Parlametra. 


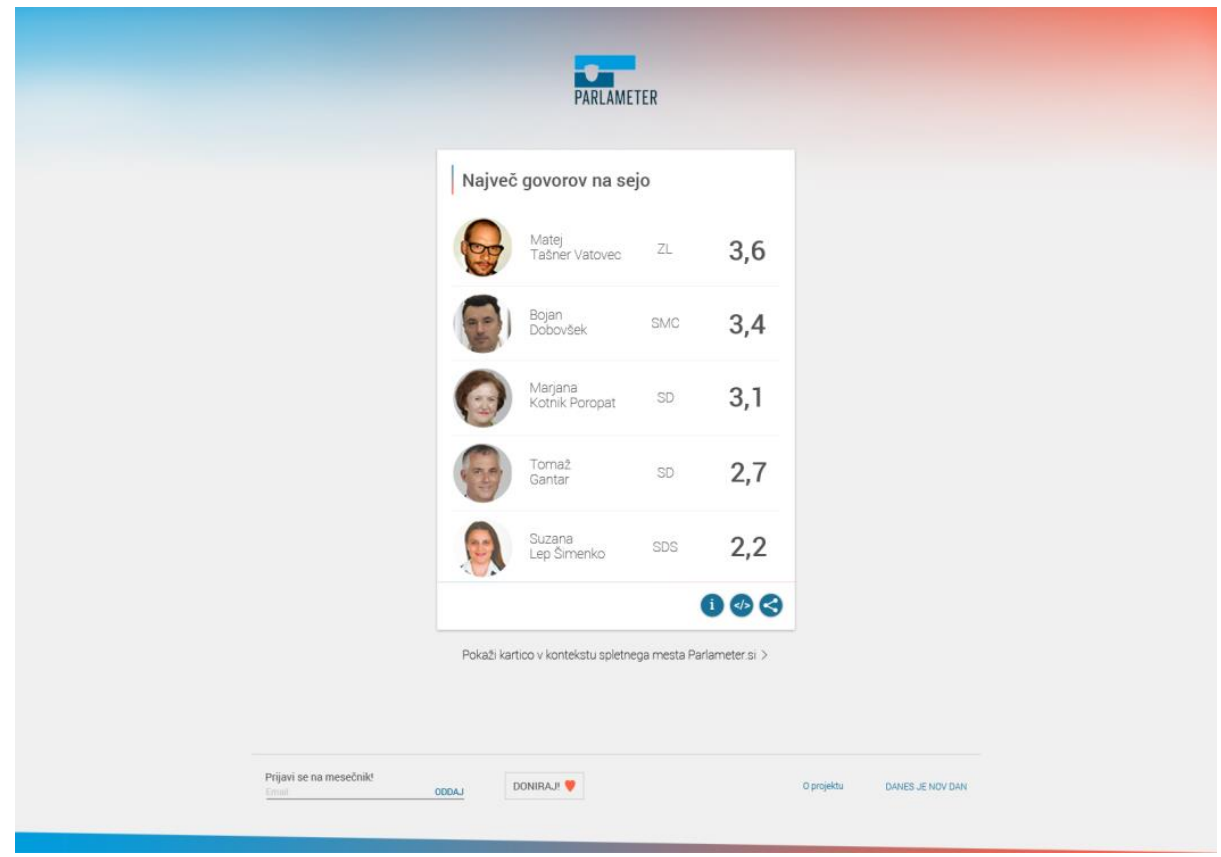

Slika 2: Primer kartice.

Transkripti poslanskih govorov se obdelujejo s številnimi analizami; od štetja besed do generiranja seznamov tipičnih besed poslank oz. poslancev, izčrpnosti njihovih besednih zakladov (Slika 3) in jezikovnostilistične analize besedja, ki ga uporabljajo $\mathrm{v}$ svojih nastopih, ter iskanja besed in besednih nizov po lematiziranih transkriptih sej (glej 3.2 in dalje). 


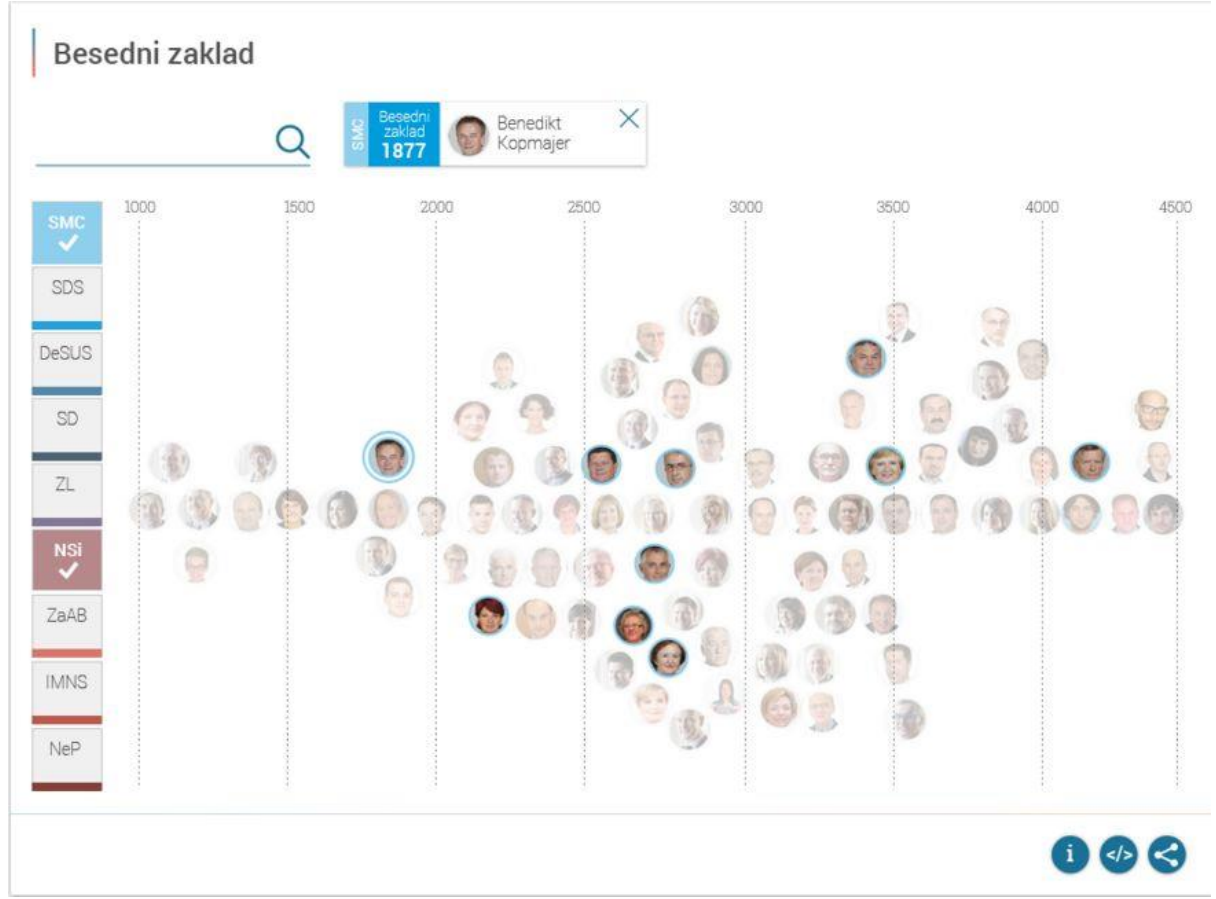

Slika 3: Prikaz besednega zaklada vseh poslancev, z izpostavitvijo izbrane poslanske skupine in izbranega posameznika znotraj nje.

\subsection{Jezikovno-stilni vidiki}

Eden od poglavitnih in zelo kompleksnih ciljev, ki so si jih zadali ustvarjalci Parlametra, je čim bolj večplastna analiza transkriptov sej državnega zbora in njegovih delovnih teles. Del analiz je tipskih (gl. spodaj) in bodo uporabniku Parlametra takoj dostopne. Pri teh sta osnovni enoti analize 'vsi govori poslanca/-ke' in 'vsi govori poslancev poslanske skupine'; nekatere analize so vezane le na prvo, druge na obe enoti. Druga možnost pa je analiziranje Parlametra glede na iskalni niz - možnosti, ki jih to odpira, natančneje predstavljamo v podpoglavju 3.2.2. Za potrebe večine analiz so vsa besedila, vključena v Parlameter, predhodno lematizirana (za lematizacijo se uporablja knjižnica LemmaGen). V nadaljevanju na kratko predstavljamo tipe in načine razčlemb, ki bodo uporabniku Parlametra dostopne takoj; zadnji se bomo v 
naslednjem podpoglavju posvetili nekoliko natančneje.

a) Besedni zaklad: izračunava se tako na ravni poslanca/-ke kot na ravni poslanske skupine. Osnova so vsi govori poslanca/-ke (oz. govori vseh poslancev poslanske skupine), ki se jih okrni s slovenskim krnilnikom LemmaGen. V okrnjenem besedilu se preštejejo vse unikatne leme, ki se nato za vsakega poslanca/-ko oz. poslansko skupino delijo s številom vseh unikatnih besed, izrečenih v državnem zboru. Tako dobljena mera besednega zaklada glede na celotni državni zbor se nato normalizira (min 1 - max 100).

b) Število izgovorjenih besed je preprosta statistika, pri kateri se v vseh govorih poslanca/-ke zgolj preštejejo vse besede v transkriptih. Na ravni poslanske skupine se ta analiza ne opravlja.

c) Povprečno število govorov na sejo: preštejejo se vsi govori poslanca/-ke, število se deli s številom sej. Nato se preštejejo vsi govori, število se najprej deli s številom poslancev, nato še s številom sej. Za končno vrednost se prvi rezultat deli z drugim. Tudi ta statistika se opravlja le na ravni posameznika.

č) Besede, ki ga/jo/jih delajo posebne: analiza se opravlja po statistiki tf-idf7; korpus predstavljajo vsi govori, dokument pa govori poslanca/-ke oziroma pri poslanski skupini govori vseh njenih članov.

d) Stilne analize predstavljajo poskus avtomatiziranega razčlenjevanja govora glede na tri vnaprej oblikovane tipe izbir besedja; izhodišča in način analize predstavljamo v naslednjem podpoglavju.

\subsubsection{STILNO OPREDELJEVANJE BESEDJA POSLANCEV IN POSLANSKIH SKUPIN}

Stilno tipizacijo besedja pri posameznikih in poslanskih skupinah je treba

7 Tf-idf je krajšava za angl. frequency-inverse document frequency. Gre za numerično statistiko, katere namen je ugotoviti, kako pomembna je dana beseda v dokumentu oz. korpusu. Pogosto se uporablja kot obtežitveni faktor pri pridobivanju informacij in besedilnem rudarjenju. 
razumeti kot poskus znotraj trenutnih možnosti in omejitev. Želja ustvarjalcev Parlametra je bila pridobiti nabor oznak iz že obstoječih leksikalnih zbirk, ki bi omogočile avtomatsko stilno označitev besedja glede na predhodno določene prevladujoče tipe govora. ${ }^{8}$ Izkazalo se je, da sta trenutno edini splošni elektronski leksikografski zbirki, ki vključujeta oznake (vsaj posredno) stilne narave, Slovar slovenskega knjižnega jezika (SSKJ) in Slovar novejšega besedja (SNB). Oba slovarja sta sicer primarno slovarja pisnega jezika, čeprav vključujeta tudi (prvotno) govorne prvine. A kot ugotavlja Verdonik (2015), govorjenost proti pisnosti ni edina upoštevanja vredna dimenzija, temveč je treba vzeti v obzir še druge, npr. formalnost proti neformalnosti, temo pogovora, naravo komunikacijskih ciljev ipd. Ker gre pri parlamentarnem diskurzu za visoko stopnjo formalnosti, velikokrat tudi vnaprejšnje pripravljenosti govora (vsaj v obliki opornih točk, delov govora), predvidevamo, da je relativna časovna odmaknjenost gradiva, zlasti v SSKJ, večja ovira kot pa dejstvo, da gre pri transkriptih v Parlametru za primarno govorjena besedila. V nadaljevanju na kratko predstavljamo načela (stilnega) označevanja leksike v obeh slovarjih in skupine kvalifikatorjev, ki določajo tipe besedja v Parlametru.

SSKJ se je z obsežnim naborom različnih vrst kvalifikatorjev (in kvalifikatorskih pojasnil) odmaknil od prej pogostega pavšalnega razlikovanja besed "po tem, ali so pravilne ali ne« (Suhadolnik 1968: 221), kar se je večinoma ocenjevalo z nejezikovnimi merili. Izhodišče za vrednotenje v SSKJ so bila nevtralna izrazna sredstva slovenskega knjižnega jezika, torej taka, ki so predvidoma nevtralna na vseh področjih (zvrstno in stilno) (Hajnšek Holz in Novak 1970). Ta so bila v slovar uvrščena brez kvalifikatorjev vrednotenja in so tvorila okvir, v katerega so bile s pomočjo kvalifikatorjev (in kvalifikatorskih pojasnil) vstavljene posebnosti, dvojnosti in izjeme: »Slovar bo o vsaki besedi, o vsakem pomenu in obliki povedal, kdaj, kje in kako jo je mogoče uporabiti, da

8 Prvotni nabor kvalifikatorjev za posamezne stilne tipe (le iz SSKJ) so opravili snovalci Parlametra sami, pri končnem oblikovanju nabora (tudi iz SNB) pa sta jim svetovali še jezikoslovki Tina Lengar Verovnik (ena od soavtoric prispevka) in Nataša Logar. 
bo zvenela nevtralno, ali pa bo nakazal smer do nevtralnega knjižnega izraza « (Suhadolnik: n. m.). Zaznamovanost v SSKJ torej temelji na razmerju ustrezno - neustrezno (v knjižnem jeziku oziroma posameznih socialnih/funkcijskih zvrsteh) in na konceptu t. i. informativne normativnosti; sodobni leksikografski pristopi to poskušajo presegati $\mathrm{s}$ postavljanjem komunikacijske oz. sporočanjske informativnosti v izhodišče slovarskega opisa (gl. Kalin Golob in Gantar 2015: 456-457). SNB, ki zajema gradivo po letu 1991, tj. po izidu zadnje knjige SSKJ, se po zgradbi navezuje na SSKJ, po vsebini in namenu pa ga dopolnjuje. V izhodišču privzema enako logiko označevanja leksike $\mathrm{s}$ kvalifikatorji in kvalifikatorskimi pojasnili, vendar se $\mathrm{v}$ podrobnostih od predhodnika ponekod razlikuje. Pri ekspresivnih kvalifikatorjih denimo uporablja le tri (SSKJ jih ima osem). V nabor kvalifikatorjev za prvi tip besedja (gl. spodaj) se zato ni uvrstil noben od kvalifikatorjev iz SNB, za drugi tip besedja (gl. spodaj) pa le en, ki pa je glede na SSKJ širši (gl. spodaj).

Po pregledu uvodnih opredelitev posameznih (skupin) kvalifikatorjev v obeh slovarjih, pregledu znatnega dela geselskih sestavkov s potencialno uporabnimi kvalifikatorji ter ob hkratnem prilagajanju števila in značilnosti tipov govora glede na izbiro besedja so bili oblikovani spodaj opredeljeni trije, vsak s pripisanimi kvalifikatorji iz SSKJ in SNB.

Prva in druga skupina umeščata govorca na os med privzdignjenim tipom govora in govorom, $v$ katerem je opaznejše poseganje po besedju iz zasebnih diskurzov.

\section{Privzdignjeno besedje}

SSKJ: evfemistično (evfem.) - beseda, s katero se izognemo neprijetnemu, včasih tudi neprimernemu izrazu; mitologija (mitol.); pesniško (pesn.) beseda, značilna za pesništvo in pesniško prozo, zlasti za tisto, ki je časovno malo odmaknjena; knjižno (kasneje redefinirano kot ozkoknjižno) (knjiž.) beseda, ki se rabi zlasti v leposlovnem ali znanstvenem jeziku, v pogovornem jeziku zveni nenavadno; zastarelo (zastar.) - nekoč rabljena beseda, danes je v 
knjižnem jeziku mrtva; starinsko (star.) - beseda, ki je bila nekoč (v kaki funkciji) splošno rabljena, danes ima arhaično patino

SNB: /

\section{Preprosto besedje}

SSKJ: narečno (nar.) - beseda, vzeta iz narečja; pogovorno (pog.) - beseda iz vsakdanje govorice ljudi, ki ne govorijo v narečju; nižje pogovorno (nižje pog.) - beseda iz nižje plasti pogovornega jezika

SNB: pogovorno (pog.) - beseda, značilna za govorjeni jezik, v zapisih pa uporabljena zlasti v nestrokovnih revijah

\section{Problematično besedje ${ }^{9}$}

Za razliko od prve in druge skupine, ki tvorita nekakšen polariziran par, predstavlja nabor kvalifikatorjev za ta tip besedja orientacijsko točko za zaznavanje možnega neprimernega ali celo sovražnega govora. Iz obeh slovarskih del so bili kot možni signali za tak govor izbrani naslednji kvalifikatorji:

SSKJ: vulgarno (vulg.) - nespodobna, prostaška beseda; slabšalno (slabš.) zaničljiva, prezirljiva beseda; ekspresivno (ekspr.) - močno čustveno obarvana beseda; ironično (iron.) - beseda, ki izraža prikrit posmeh in ima pogosto nasproten pomen od izhodiščnega; otroško (otr.) - beseda, ki jo rabijo otroci ali starejši v pogovoru z njimi (v nabor uvrščena zaradi mesta tvorjenja govora, kjer naravnih diskurzivnih okoliščin za tako besedje ni)

SNB: slabšalno (slabš.) - beseda, ki izraža izrazito odklonilen odnos do poimenovanega; vulgarno (vulg.) - besede, ki so širše družbeno nesprejemljive za vsakdanje komuniciranje

9 Avtorice prispevka se strinjajo s pripombo enega od recenzentov, da bi bilo ta tip bolje imenovati ekscesno besedje. Predlog so že posredovale v presojo tvorcem Parlametra. 
Sezname besed z vsemi kvalifikatorji je pripravil Amebis, d. o. o. Pri tem je treba poudariti, da gre vedno za oznake na ravni iztočnic, saj so bili upoštevani le kvalifikatorji, ki so tik za zaglavjem in imajo doseg do konca geselskega sestavka (ne pa tudi kvalifikatorji za posamezne pomene oziroma rabe). V Parlametru se pri vsakem poslancu/-ki izriše črtni graf, ki prikazuje delež posameznega tipa besedja v njegovih/njenih govorih glede na povprečje, izračunano za celotni sklic (Slika 4). Delež se izračuna po naslednjem algoritmu: vzamejo se vsi govori poslanca/-ke, prešteje se število besed (in njihovih ponovitev) v vsaki kategoriji besedja. To se izvede za vse poslance, nato se deli vrednost kategorije za posameznika z vrednostjo povprečja (seštevek vrednosti vseh poslancev, deljen $\mathrm{s}$ številom poslancev). Vrednost vsake kategorije za vsakega poslanca/-ko se normalizira (min. 1 - max. 100). Izračun se izvaja tudi na ravni poslanske skupine, ne pa (še) na primer na ravni govora ali izbranih govorov, kar bi bilo zanimivo zlasti za jezikoslovnostilistične raziskave (gl. naslednje poglavje).

\section{Stilne analize}

Privzdignjeno
besedje

Preprosto

besedje

Problematično besedje
MGZ

Povprečje

MGZ

Povprečje

MGZ

Povprečje

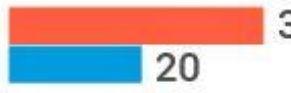

35

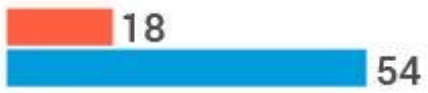

54

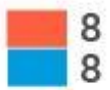

\section{i) $<>$}

Slika 4: Deleži tipov besedja v govorih izbranega posameznika glede na povprečja vseh poslancev. 


\subsubsection{PARLAMETER KOT JEZIKOVNI VIR}

Ker so transkripti govorov poslancev v Parlametru lematizirani, bo mogoče po njih opravljati iskanje posameznih besed, pa tudi besednih nizov. Pri tem bo mogoče iskanje omejiti glede na naslednje filtre: poslanec/poslanska skupina; časovno obdobje (mesec, leto); vrsta sej (seje državnega zbora, seje kolegija državnega zbora, seje (posameznih) delovnih teles). Pri besednih nizih je privzeti način iskanja široko ujemanje (vsi govori, ki vsebujejo katerokoli od vpisanih besed $v$ iskalnem nizu). Možni so še štirje drugi načini: povezovanje z IN (zgolj zadetki z vsemi besedami v iskalnem nizu), iskanje z narekovaji (samo zadetki s točnim naborom znakov), iskanje $\mathrm{s}+$ (s plusom označena beseda iz iskalnega niza bo nujno prisotna v zadetkih, druge pa služijo le rangiranju rezultatov), iskanje z - (zadetki izključujejo besedo, označeno z minusom).

Uporabniku Parlametra se bodo ob vsakem iskanju prikazale štiri samodejno generirane vrste razčlemb. V nadaljevanju jih bomo na kratko opisali, nato pa bomo nakazali še nekaj možnosti, ki jih Parlameter kot notranje strukturirana in označena zbirka podatkov $\mathrm{v}$ elektronski obliki odpira za jezikoslovne raziskave.

a) Raba skozi čas: ker je vsak govor označen z datumom, jih je mogoče združiti po mesecih in prešteti pojavitve leme iskanega niza. Na črtnem grafu se izpiše število pojavitev za vsak mesec.

b) Največkrat so pojem uporabili: za vsakega poslanca/-ko se prešteje število pojavitev leme iskanega niza $\mathrm{v}$ vseh govorih. Osebe so razvrščene glede na število pojavitev, prikazanih je prvih pet (Slika 5 ).

c) Priljubljenost po poslanskih skupinah je prikaz števila pojavitev leme iskanega niza $\mathrm{v}$ vseh govorih poslancev posameznih poslanskih skupin na krožnem grafikonu.

č) Nastopi, v katerih je bil iskani niz izrečen: povezave do vseh govorov, v katerih je bil iskani niz izrečen, se izpišejo v obliki razširjenih konkordanc. Te 
so identificirane z govorci in datumi nastopov - zadetki so izpisani po datumu, od najnovejšega do najstarejšega (Slika 6).

\section{Največkrat so pojem uporabili}

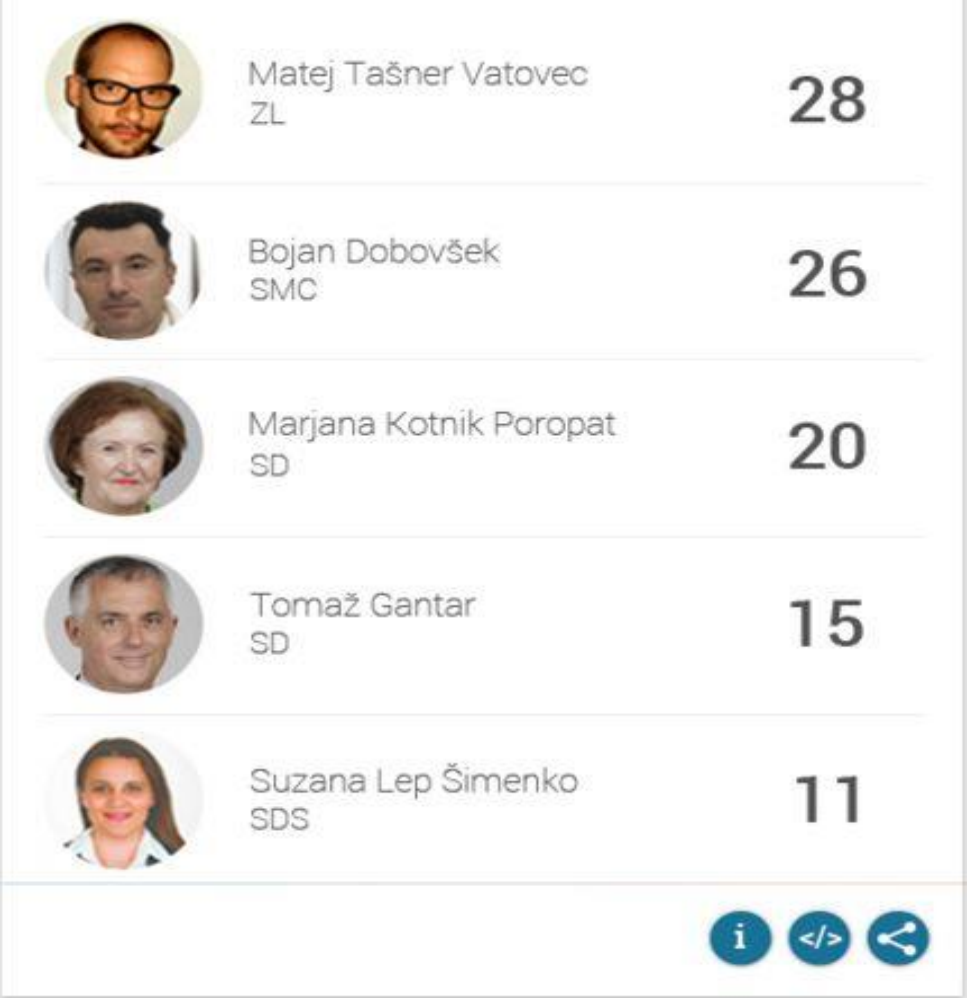

Slika 5: Prikaz petih poslancev, ki so v svojih govorih najpogosteje uporabili iskani niz. 
Nastopi, v katerih je bil iskalni niz izrečen

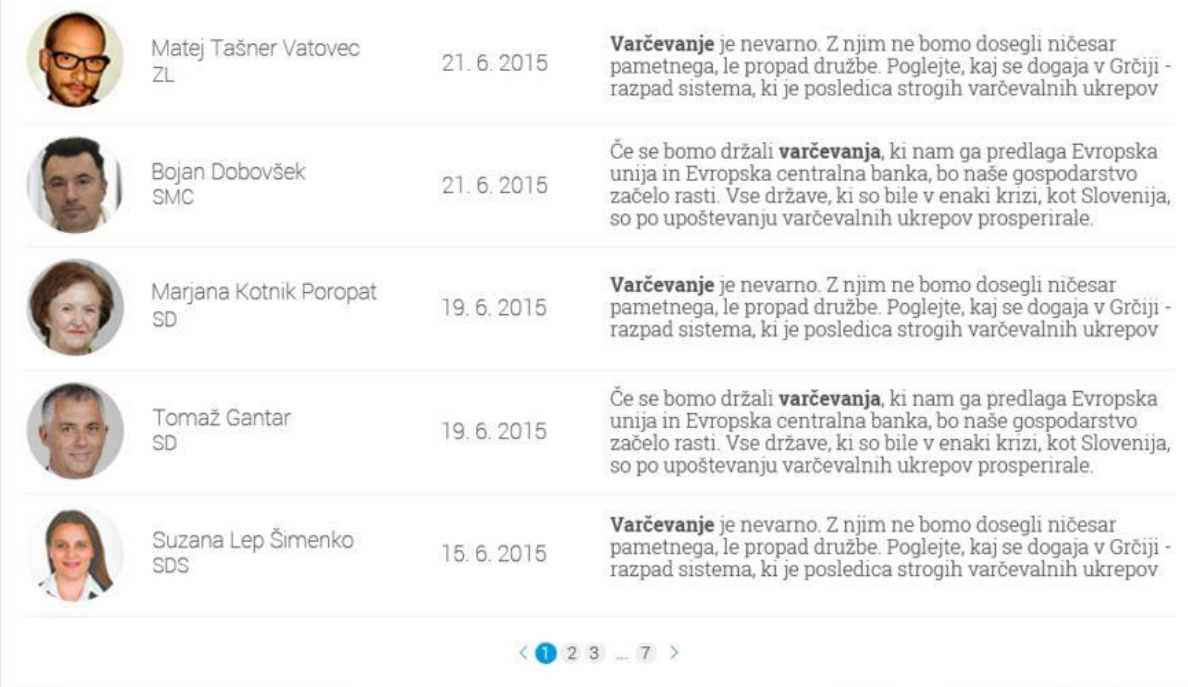

(i) 180

Slika 6: Del izpisa povezav do nastopov, v katerih so poslanci izgovorili iskani niz.

Naštete možnosti iskanja in analiz dobljenih zadetkov zelo spominjajo na poizvedovanja, ki jih lahko opravljamo v jezikovnih korpusih. Parlameter seveda ni jezikovni korpus, saj kot elektronska zbirka podatkov ni bil oblikovan, da bi primarno omogočal jezikoslovne opise in analize (Kennedy 1999: 57). Lahko pa ga uporabljamo kot jezikovni vir, ki ima to prednost, da že prek vmesnika omogoča marsikatero za jezikoslovca dobrodošlo razčlembo. Zlasti je zanimiv njegov dinamični značaj - korpus lematiziranih transkriptov se bo sproti osveževal, in sicer najkasneje 24 ur po objavi transkriptov govorov na spletni strani državnega zbora. $\mathrm{V}$ tem je podoben t. i. spremljevalnemu tipu korpusa (angl. monitor corpus), v katerega se gradivo dodaja sproti, s čimer se udejanja princip razvojnosti, dinamičnega spremljanja jezikovnega razvoja. Referenčni sinhroni korpusi so - kljub svojemu imenu - zaradi doseganja uravnoteženosti namreč večinoma statični (Gorjanc 2005; Kennedy 1999). 


\subsection{Način aplikacije Parlametra na izbrane primere analize}

Uporabnost Parlametra v jezikovne namene lahko prikažemo na naslednjem potencialnem primeru. V zadnjem letu je javni, zlasti medijski diskurz kolebal med izrazi migrant, begunec in prebežnik (gl. npr. vprašanje in odgovor na to temo na spletišču Terminologišče Inštituta za slovenski jezik Frana Ramovša pri ZRC SAZU). Čeprav ima slednji v rabi pogosto pomenski odtenek 'prebežnik iz boja', tj. dezerter (prim. SSKJ), se ga je precejšen del medijske produkcije oklenil kot rešilne bilke v dilemi med izbiro pomensko širokega, a prevzetega migranta in domačega begunca, pomensko vezanega na neekonomske migrante. Zanimivo bi bilo analizirati, kaj bi pokazala različna iskanja po gradivu Parlametra: ali gre pri izbiranju enega, drugega ali tretjega izraza za časovna nihanja? Morda za različno distribucijo glede na poslanske skupine? Glede na tipe besedja? Glede na odnos do jezika, ki bi ga lahko razbrali šele s kvalitativno analizo govorov, vezanih na slovenščino in odnos poslancev do nje? In kam se umešča redkeje rabljeni izraz pribežnik ('kdor kam pribeži')? Podobno bi lahko dinamiko, distribucijo in implikacije rabe opazovali tudi pri izrazih (rezilna) žica in tehnična ovira, ki sta v slovenskem javnem diskurzu tako nova izraza, da ju v tem pomenu ne zajema noben od jezikovnih korpusov. Zanimive pa bi bile seveda tudi družbene implikacije, ki sledijo iz primarno jezikoslovnih ugotovitev in bi jih bilo nedvomno mogoče povezati s primarnimi analizami in uvidi, ki jim je Parlameter sploh namenjen (gl. 3.1).

$\mathrm{Z}$ omogočenjem analize tipov besedja na ravni posameznih govorov ali podkorpusov govorov (zdaj je to mogoče le na ravni posameznika ali poslanske skupine) pa bi se odprle možnosti tudi za zanimive jezikovnostilistične raziskave. Govori z nadpovprečno visokim deležem problematičnega besedja bi na primer lahko bili izhodišče za raziskovanje eksplicitnega žaljivega ali sovražnega govora, tj. govora, ki vsebuje neposredne indice žaljivosti, sovražnosti ipd. (kot ugotavlja Kalin Golob (2002), so indici pogosto posredni, doseženi z adherentno zaznamovanimi jezikovnimi sredstvi). Ročna analiza teh istih besedil pa bi ustvarjalcem Parlametra po drugi strani ponudila povratne 
informacije o tem, kolikšna je sploh natančnost in zato relevantnost samodejnih označitev tipov besedja - v smislu deleža zajema leksike glede na vse lekseme, ki bi jih lahko označili za »problematične«, "privzdignjene« ali "preproste« (skladno z zgornjimi opredelitvami), ter v primerjavi s celovitim stilnim učinkom, ki ga (lahko) ima neki govor. Zavedamo se namreč, da je inherentno zaznamovana leksika le del orodja pri doseganju želenega stilnega učinka (ironije, sarkazma, napadalnosti, žaljivosti, sovražnosti ipd.) in da je te učinke - ob upoštevanju besedilnega in nejezikovnega konteksta - mogoče dosegati tudi s (slovarsko) popolnoma nevtralnimi leksikalnimi sredstvi. V prihodnje je zato načrtovana tudi primerjava rezultatov samodejne analize besedja z rezultati ročne analize in $\mathrm{z}$ rezultati celovitejše jezikovnostilistične analize na reprezentativnem naboru govorov poslancev.

Zanimive pa bi bile seveda tudi družbene implikacije, ki sledijo iz primarno jezikoslovnih ugotovitev in bi jih bilo nedvomno mogoče povezati s primarnimi analizami in uvidi, ki jim je Parlameter sploh namenjen (gl. 3.1). V prihodnjih fazah razvoja bo mogoče tudi iskanje korelacij med posameznimi analizami. Zanimivo bo iskati morebitne korelacije med prisotnostjo, glasovanji in jezikovnimi rabami, pa tudi morebitnimi novimi podatki, ki jih bo orodje vključevalo, ko bodo dostopni, npr. poročanja o lobističnih stikih. Sam Parlameter bo omogočal iskanje tovrstnih korelacij, medtem ko bo interpretacija na ravni rezultatov prepuščena uporabnikom.

Zato velja v pričujočem prispevku že vnaprej opozoriti na potencialne dvoumne sklepe. Obstaja namreč verjetnost, da bodo na podlagi enakih podatkov različno angažirani uporabniki prišli do zelo različnih, če ne kar nasprotujočih si ugotovitev, sploh v primerih, če bodo njihove posamične analize izvzete iz konteksta ter razložene pretirano poenostavljeno in načrtno pristransko. Inštitut Danes je nov dan v okviru orodja Parlameter ne bo objavljal lastnih vsebinskih interpretacij analitično pridobljenih rezultatov, saj je primarni cilj projekta predvsem odpirati javni dostop do informacij ter tako (strokovno in splošno) javnost opolnomočiti v smeri oblikovanja lastnih zaključkov. Medijske 
objave, ki se nanašajo na delo parlamenta, so že zdaj pogosto poenostavljene, izvzete iz konteksta in predstavljene pristransko, s Parlametrom pa se odpira možnost, da na podlagi empirično preverljivih informacij in podatkov vsakdo pride do lastnih zaključkov. Če karikiramo: to, da bodo na podlagi enakih podatkov do enako relevantnih zaključkov lahko prišli tako novinarji Reporterja kot Mladine, se zdi prej prednost kot pomanjkljivost samega orodja. Pomemben vidik večanja transparentnosti in nadzora nad odločevalci je namreč tudi angažma in politična pismenost prebivalcev, za to pa je nujen dostop do materialov, ki jih iz razdrobljenih podatkov Parlameter organizira v jasne kategorije in informacijske sklope. Inštitut Danes je nov dan se z drugimi projekti sicer oglaša angažirano in ponuja vsebinske interpretacije, nagovarja pa tudi k politični participaciji in odgovornosti za lastno opolnomočenje, zato napoveduje, da bo lastne analize podatkov s Parlametra objavljal na spletnem mestu danesjenovdan.si/obcasnik, medtem ko bo Parlameter deloval zgolj na podlagi merljivih kazalcev.

\section{ZAKLJUČEK}

Poleg omenjenih specifik orodje ponuja še precej možnosti za (samo)nadgradnjo in dodatno analizo. $\mathrm{V}$ sklopu jezikovnih analiz je identificiranje skupin besedja prek slovarskih kvalifikatorjev zagotovo le začetna možnost, ki bi jo bilo treba nadgrajevati ob novih spoznanjih in predvsem ob novih slovarskih in drugih leksikalnih zbirkah. Zanimiva izhodišča se ponujajo npr. v Kalin Golob in Gantar (2015): v sodobni leksikografiji, podprti s korpusi, se možnosti označevanja spreminjajo, zaradi (spletne) neomejenosti s prostorom pa niso več omejene le na okrajšave kvalifikatorjev. Označevanje kontekstualno in diskurzno specifične ter stilno opazne rabe s tem postaja veliko bolj raznotero in večplastno ter - ko govorimo o slovarski obravnavi in prikazu - razpršeno po geselski zgradbi (gl. n. d.: 457463). To po eni strani pomeni, da bo treba opraviti veliko kompleksnejše premisleke o uporabi oznak in zlasti drugih, manj enovitih načinov 
informiranja o komunikacijskih in drugih učinkih rabe posameznih jezikovnih sredstev pri postopkih samodejnega prepoznavanja tipov besedja. Po drugi strani pa spletno okolje analize gradiva in predstavitve podatkov tako pri korpusnih leksikografskih delih kot pri platformah tipa Parlameter lahko predstavlja prednost, saj je sinergije ob skupni osnovi najbrž laže najti.

Še eno možno smer premisleka o označevanju stilnih tipov govora nakazuje drug primer iz slovenskega okolja. Za korpus uporabniških vsebin Janes, ki nastaja v okviru projekta Jezikoslovna analiza nestandardne slovenščine in v katerem so zbrana besedila spletne slovenščine (iz besedil forumov, blogov, komentarjev na novice in tvitov), so njegovi ustvarjalci preizkusili tudi označevanje prevladujočega sentimenta - pozitivnega, nevtralnega in negativnega. S pripisom sentimenta npr. tvitom o določeni temi je namreč mogoče ugotavljati (ne)naklonjenost javnosti posameznim temam oziroma trende v sentimentu na določeno temo. Po začetni fazi ročnega pripisovanja sentimenta večji količini tvitov so prešli na avtomatizirano pripisovanje $s$ posebej prirejenim računalniškim programom oziroma modelom (več v Erjavec, Fišer in Ljubešić 2015). Čeprav avtorji ob medsebojni primerjavi označevanja pri dveh anotatorjih in nato še ročnega $s$ samodejnim označevanjem ugotavljajo, da je avtomatsko označevanje po kakovosti na sredini med naključnim in ročnim pripisovanjem sentimenta, pa je to gotovo ena od možnih poti, ki bi jih bilo pri nadaljnjem razvoju Parlametra (zlasti pri opredeljevanju tipov besedja ali celo širše definiranih stilnih tipov) vredno preizkusiti.

Za nadaljnji razvoj orodja je nujno omogočiti tudi dostop do trenutno neobstoječih podatkov - tistih, ki bodisi niso objavljeni na spletu ali pa so objavljeni v strojno neberljivi obliki. Gre npr. za podatke o glasovanjih na sejah odborov in delovnih teles, podatke o prejetih opominih, proceduralnih vprašanjih, pa tudi za imena poslank/-cev predlagateljic/-ev posameznih zakonov oz. amandmajev, pa tudi za videoposnetke sej nacionalne televizije. $\mathrm{Ne}$ glede na naštete razvojne potenciale, ki že predstavljajo nove izzive za še 
povsem nov projekt, kot je Parlameter, pa bo že sedanja verzija ponudila vrsto novih možnosti za vpogled, analizo in interpretacijo dela poslancev, poslanskih skupin in posameznih političnih strank. Te možnosti pa ne bodo omejene zgolj na stroko in specifične raziskovalne ali publicistične interese, temveč bodo skozi odprto platformo na voljo vsem, ki se bodo želeli podrobneje seznaniti bodisi z jezikovno bodisi z vsebinsko sliko dela v parlamentu.

\section{LITERATURA}

Bellamy, C., in Rabb, C. D. (1999): Wiring-up the Deck-Chairs? V S. Coleman (ur.): Parliament in the Age of the internet: 156-172. Oxford: Oxford University Press.

Coleman, S., Taylor, J., in van de Donk, W. (1999): Parliament in the Age of the internet. Oxford: Oxford University Press.

Dahlgren, P. (2013): The Political Web. London: Routdlege.

Erjavec, T., Fišer, D. in Ljubešić, N. (2015): Razvoj korpusa slovenskih uporabniških vsebin Janes. V D. Fišer (ur.): Zbornik konference Slovenščina na spletu in v novih medijih, Ljubljana, 25.-27. november 2015 (elektronski vir). Dostopno prek: http://nl.ijs.si/janes/wpcontent/uploads/2015/11/JANES15-04-Razvoj-korpusa.pdf (2. 4. 2016).

Golbeck, J., Grimes, J. M., in Rogers, A. (2010): Twitter Use by the U.S. Congress. Journal of the American Society for Information Science and Technology, 61 (6): 1612-1621.

Gorjanc, V. (2005): Uvod v korpusno jezikoslovje. Domžale: Založba Izolit.

Hajnšek Holz, M., in Novak, F. (1970): Kvalifikatorji. Naši razgledi, 19: 140.

Joshi, D., in Rosenfield, E. (2013): MP Transparency, Communication Links and Social Media: A comparative assessment of 184 Parliamentary Websites. The Journal of Legislative Studies, 19 (4): 526-545.

Kalin Golob, M., in Gantar, P. (2015): Stilistika in enojezični slovar: označevanje jezikovne variantnosti. V V. Gorjanc in dr.: Slovar sodobne slovenščine: problemi in rešitve: 446-465. Ljubljana: Znanstvena založba Filozofske fakultete. 
Kalin Golob, M. (2002): Jezikovna stilistika in razžalitve v tiskanih medijih. V T. Korošec in dr.: Razžalitve $v$ tiskanih medijih: 31-46. Ljubljana: Fakulteta za družbene vede.

Kennedy, G. (1999): An Introduction to Corpus Linguistics. London; New York: Longman.

Lofgren, K., Andersen, K. V., in Sorensen, M. F. (1999): The Danish Parliament going Virtual. V S. Coleman in dr. (ur.): Parliament in the Age of the Internet: 131-140. Oxford: Oxford University Press.

Mance, B. (2014): Odnosi med novinarji in politiki na Twitterju: Od profesionalizma do »odmevne komore«. Javnost/The Public, 21: S23S40.

Oblak Črnič, T. (2010): Preobrazbe na spletu: od infopromocijske k individualizirani politiki? Teorija in praksa, 47 (1): 22-40.

Oblak Črnič, T., in Amon Prodnik, J. (2014): Samopromocijski novičarski mediji? Analiza spletnih mest slovenskih političnih akterjev. Teorija in praksa, 51 (6): 1321-1343.

Oblak, T. (2003): Izzivi e-demokracije. Ljubljana: FDV.

Taylor, A. J., in Burt, E. (1999): Parliaments on the web: Learning through Innovation. V S. Coleman in dr. (ur.): Parliament in the Age of the internet: 141-155. Oxford: Oxford University Press.

Slovar novejšega besedja. Zgradba. Dostopno prek: http://www.fran.si/130/sskjslovar-slovenskega-knjiznega-jezika/datoteke/SSKJ_Uvod.pdf (2. 4. 2016).

Slovar slovenskega knjižnega jezika. Uvod. Dostopno prek:

http://www.fran.si/131/snb-slovar-novejsega-besedja/datoteke/SNB_Zgradba.pdf (2. 4. 2016).

Suhadolnik, S. (1968): Koncept novega slovarja slovenskega knjižnega jezika. Jezik in slovstvo, 13 (7): 219-224.

Verdonik, D. (2015): Govorjeni proti pisnemu ali katera leksika je »tipično govorjena «. V V. Gorjanc in dr.: Slovar sodobne slovenščine: problemi in rešitve: 392-405. Ljubljana: Znanstvena založba Filozofske fakultete. 


\section{SPEECH AND FUNCTIONING OF POLITICAL ELITES THROUGH THE LENS OF PARLAMETER}

The article discusses several aspects of speech used by established political elites in the context of a developing digital tool Parlameter. This is done without understanding the internet and digital spaces as always already stylistically marked. Instead, they are understood as a platform that also provides a possibility for critical analysis of language as a social phenomenon. Parlameter allows for analysis of »live « language, which always has an important context, as it is spoken by MPs - legislative decision makers, who shape the culture of public expression. Analysis is done using diverse algorithms and structural mechanisms - from examining the use of language to calculating MP's presence and decisions in the parliament. The article discusses the automated and other analyzes offered by Parlameter. Units analyzed are individual MPs and parliamentary groups in the current parliamentary session. Since Parlameter, as an emerging analytical tool, also has a supervisory function in addition to the linguistic-stylistic dimensions, the former are also described and placed in a wider context of digitization of institutional policy.

Keywords: the parliament, speech analysis, digital platforms, Parlameter

To delo je ponujeno pod licenco Creative Commons: Priznanje avtorstvaDeljenje pod enakimi pogoji 4.0 Slovenija.

This work is licensed under the Creative Commons Attribution ShareAlike 4.0 License Slovenia.

http://creativecommons.org/licenses/by/4.o/

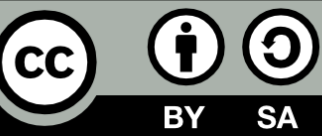

